\title{
AS DOENÇAS NEGLIGENCIADAS NAS MÍDIAS DIGl- TAIS: o processo social saúde-doença, imaginário e efeitos-sentidos
}

\author{
Lucineia Oliveira \\ (UESB) \\ https://orcid.org/0000-0003-0718-2911 \\ Gerenice Ribeiro Oliveira Cortes \\ (UESB) \\ http://orcid.org/0000-0001-6597-6192
}

\section{RESUMO}

O presente trabalho tem por objetivo analisar, à luz da Análise de Discurso, fundada por Pêcheux $(1969,1975,1983)$, a discursivização das Doenças Tropicais Negligenciadas (DTNs) na mídia digital, com foco no processo social saúde-doença. O corpus foi constituído de dez sequências discursivas (SD) coletadas a partir de duas publicações dos sites UOL e G1. Nesta análise foram mobilizadas, além do conceito de discurso, as noções de sujeito, memória discursiva, projeções imaginárias e silenciamento; ademais, também mobilizamos algumas contribuições teóricas do campo das ciências sociais. Os resultados apontam que as DTNs tanto são sintomas como efeitos da desigualdade social existente no país; os efeitos de descaso e silenciamento para com as DTNs já se inscrevem no próprio nome dessas doenças, pelo viés dos sentidos de negligência; além disso, há silenciamento de sentidos no discurso oficial do poder público, pelo não enfrentamento dessa grave questão, como também no discurso das indústrias farmacêuticas, tendo em vista o jogo de interesses econômicos, pois as DTNs são discursivizadas pelo imaginário de doenças de pobres.

PALAVRAS-CHAVES: Doenças Negligenciadas; Mídia jornalística Digital; Imaginário Silenciamento. 


\section{THE NEGLECTED DISEASES IN THE DIGITAL MEDIA: the health-disease social process, imagination and speech effects}

\section{ABSTRACT}

This work aims at analyzing, in the light of the Speech Analysis founded by Pêcheux $(1969,1975,1983)$ the discursiveness of the Neglected Tropical Diseases (NTDs) in the digital media focusing in the health-disease social process. The corpus was composed of ten discursive sequences collected from two sites, UOL and G1. In this analysis, we discussed the concepts of speech, subject, discursive memory, imagination and silencing. Furthermore, we discussed some theoretical contributions from the field of social sciences. The results point out that the NTDs are both symptoms and effects of the social disparity existing in the country; the effects of disregard and silencing towards the NTDs are inscribed in the very name of these diseases by the bias of the meanings of neglect. Moreover, there is silencing of meaning in the official speech of the public authority, via the negligence of this serious matter, as well as in the speech of the pharmaceutical industry, bearing in mind its economical interests, once the NTDs are signified by the imaginary of disease of the poor.

KEYWORDS: Discursiveness of Neglected Diseases; Digital Journalistic Media; Imagination; Silencing.

\section{Introdução}

A persistência das Doenças Tropicais Negligenciadas (DTNs) no Brasil é uma situação que coloca o país como destaque negativo pela permanência de enfermidades que já foram eliminadas em outros países, o que evidencia a situação de vulnerabilidade social de parte da população que vive em um território ideal para seu desenvolvimento.

Intrinsecamente ligadas ao fator de pobreza da população atingida, como também ao fato de que, quando não tratadas, essas doenças podem causar mutilações como a cegueira ou a morte, as DTNs segundo o Ministério da Saúde não só prevalecem em condições de pobreza, mas 
também contribuem para manutenção do quadro de desigualdade, já que representam forte entrave ao desenvolvimento do país (BRASIL, 2010).

Doença de chagas, esquistossomose mansoni, hanseníase, raiva humana, tracoma, leishmaniose tegumentar e visceral, segundo o Ministério da Saúde (MS) já atingem quase 26 milhões de pessoas no Brasil, sobretudo a população de baixa renda. Entretanto, nota-se que a abordagem desse grave problema de saúde pública nas mídias digitais é bastante incipiente.

Assim, neste estudo, nosso objetivo é analisar, à luz da Análise de Discurso, fundada por Pêcheux (1969, 1975, 1983), a discursivização das Doenças Tropicais Negligenciadas na mídia digital. Partimos da hipótese de que as DTNs são sintomas da desigualdade social e do jogo de interesses econômicos que envolve, sobretudo as indústrias farmacêuticas.

O espaço virtual aqui é considerado como um espaço discursivo de disputas territoriais de sentidos, pois "é do ponto de vista da discursividade que temos de considerar as questões relativas ao território e territorialidade, mesmo no ciberespaço" (CORTES, 2015, p. 3). Nesse jogo de forças que determinam os sentidos devemos buscar os não-ditos no interior do que é dito (PÊCHEUX, [1969] 2014), nas materialidades digitais.

Para a análise deste trabalho, o corpus foi constituído de matérias jornalísticas publicadas nos sites UOL1, G12 e de alguns comentários de leitores/internautas. A escolha desses sites se deu por fazerem parte de grandes conglomerados da comunicação brasileira: Grupo Folha e Grupo Globo. Os comentários foram coletados pelo critério da regularidade discursiva, que para a $\mathrm{AD}$ resulta da repetibilidade das materialidades discursivas, ou seja, a repetibilidade cria a regularidade de sentidos, mas nada estanque, pois os discursos funcionam em movimento de tensões constantes, os “processos regulares são aqueles que tomam 'certa direção', orientados por determinações ideológicas, mas que podem se transformar, mudar de orientação conforme o interdiscurso" (FERNANDES, VINHAS, 2019, p.142). Nesta perspectiva, as sequências discursivas estão divididas em dois blocos: Bloco 1: SD1, SD2, SD3, SD4, SD5, SD6 foram coletadas do portal G1 que segue a regularidade do discurso de denúncia contra a indústria farmacêutica; Bloco2: SD7, SD8, SD9 e SD10, coletadas do

1 UOL - Universo Online site criado em 1996 pelo Grupo Folha, informações: http://sobreuol.noticias.uol.com.br/historia/

2 G1 -É um portal de notícias mantido pelo Grupo Globo que foi criado em 2006, informações: http://historiagrupoglobo.globo.com/hgg/index.htm 
site UOL segue a regularidade do discurso parafrásticos em que o termo DTNs é substituído por outras nomenclaturas como doenças esquecidas.

\section{Pressupostos teóricos da Análise do Discurso (AD)}

A pesquisa fundamenta-se teórica e metodologicamente nos aportes da Análise de Discurso fundada por Michel Pêcheux (1969, 1975, 1983). Para o autor, o discurso é efeito de sentidos entre interlocutores (1969), os quais, para se constituírem em sujeitos, são afetados pela memória, pela ideologia e pela língua.

A AD é considerada uma disciplina de entremeio entre a Linguística, a Psicanálise e a História. No entanto, segundo Orlandi (1994), nesse entremeio entre a Linguística e as Ciências Sociais, a AD ressignifica estes conceitos, pois tem seu objeto próprio que é o discurso, de forma que o entremeio não significa interdisciplinaridade. A AD se interessa pela não-transparência da linguagem, nesta perspectiva o sentido sempre pode ser outro, pois o processo discursivo funciona nas relações com a memória, com a ideologia, no processo de movimentos de sujeitos, constituídos na relação com a língua em sua opacidade, afetados pela história.

Orlandi ([1999] 2015) preconiza que o discurso é a palavra em movimento, "com o discurso observa-se o homem falando" (ORLANDI, [1999] 2015, p. 13), e dessa forma a AD concebe a linguagem como mediação entre o homem e a sua realidade natural e social. A AD se propõe a buscar as discursividades, os efeitos de sentidos inscritos nas materialidades, não mais questionando aquilo que o interlocutor quis dizer, pois o sujeito é uma construção discursiva, determinado historicamente; assim, a literalidade dos sentidos não é considerada, mas os efeitos de sentidos e os efeitos-sujeito no jogo de relações da língua - tomada em sua opacidade - com a memória e com a ideologia.

O sujeito na $\mathrm{AD}$ é dividido e interpelado pela ideologia (PÊCHEUX, [1983] 2015), não se trata do sujeito pragmático, mas sim do sujeito discursivo, que pode ser uma posição entre outras. Nesta perspectiva, não há discurso sem sujeito e não há sujeito sem ideologia. Orlandi ([1999] 2015) lembra que na $\mathrm{AD}$ o sujeito discursivo é uma posição entre outras, "nesse sentido é que os sujeitos são intercambiáveis" (ORLANDI, [1999] 2015, p. 47), já que ele é constituído juntamente aos sentidos (PÊCHEUX, [1975] 2014).

Para Pêcheux ([1975] 2014) o discurso sempre funciona em dadas condições de produção $(\mathrm{CP})$, em uma dada conjuntura. Tais condições de produção, segundo Orlandi (2012), envolvem tanto as circunstâncias 
enunciativas quanto as determinações históricas e ideológicas, já que a constituição do discurso precede a sua formulação. Assim, as CP do discurso dizem respeito às relações de forças e relações de sentidos, já que todo discurso remete a outros discursos, em um constante processo metafórico de retomadas, substituições e paráfrases.

Ainda sobre o jogo de relações de sentidos e relações de forças, Orlandi ([1999]2015) esclarece que as relações de sentidos consistem justamente no funcionamento da memória discursiva, pois não existe discurso que não se relacione com outro, todo discurso é visto como um processo amplo e contínuo: "Não há, desse modo, começo absoluto, nem ponto final para o discurso. Um dizer tem relação com outros dizeres realizados, imaginados ou possíveis" (ORLANDI, [1999]2015, p. 37). Já a relação de forças, conforme a autora, diz respeito ao lugar a partir do qual fala $\mathrm{o}$ sujeito, sendo esse lugar constitutivo do que ele diz:

Como nossa sociedade é constituída por relações hierarquizadas, são relações de força, sustentadas no poder desses diferentes lugares, que fazem valer na 'comunicação'. A fala do professor vale (significa) mais do que a do aluno (ORLANDI, [1999] 2015, p. 37).

Todavia, na $\mathrm{AD}$ o que interessa não é o lugar físico nem o sujeito empírico, mas as projeções de suas imagens que resultam de já-ditos inscritos na memória. Para melhor explicar esse funcionamento, Orlandi mostra o seguinte exemplo:

O que funciona no discurso não é o operário visto empiricamente, mas o operário enquanto posição discursiva produzida pelas formações imaginárias. Daí que, na análise, podemos encontrar, por exemplo, o operário falando no lugar de patrão (ORLANDI, [1999] 2015, p.38).

Conforme a autora, este imaginário faz parte do funcionamento da linguagem e assenta-se no modo como a sociedade se inscreve na história e são regidas por relações de poder, ou seja, "a imagem que temos de um professor, por exemplo, não cai do céu. Ela se constitui nesse confronto simbólico com o político, em processos que ligam discursos e instituições" (ORLANDI, [1999] 2015, p. 40). Ela ainda acrescenta que:

Por isso a análise de discurso é importante. Com ela podemos atravessar esse imaginário que condiciona os sujeitos em suas discursividades e, explicitando o modo como os sentidos estão sendo produzidos, compreender melhor o que está sendo dito (ORLANDI, [1999] 2015, p. 40). 
Logo, as formações imaginárias, afetadas pela memória, determinam também a produção dos sentidos, ou seja, um único discurso remete a outro discurso, em resposta ao que já foi dito de forma direta ou indireta e pode anular ou atualizar, dando àquele discurso novo sentido: "Em outros termos, o processo discursivo não tem, de direito, início: o discurso se conjuga sempre sobre um discursivo prévio, ao qual ele atribui o papel de matéria prima" (PÊCHEUX, [1969] 2014, p.76).

Assim, uma noção central na teoria discursiva é a de memória, que não deve ser entendida no sentido psicologista da "memória individual", mas nos sentidos entrecruzados entre memória social, mítica e histórica Pêcheux ([1983] 2015). Para o autor:

A memória discursiva seria aquilo que, face a um texto que surge como acontecimento a ler, vem reestabelecer os 'implícitos' (quer dizer, mais tecnicamente, os pré-construídos elementos citados e relatados, discursos-transversos, etc.) de que sua leitura necessita: a condição do legível em relação ao próprio legível (PÊCHEUX, [1983] 2015, p. 46).

Neste sentido, Pêcheux ([1983] 2015) afirma que funciona um jogo de força na memória, sob o choque do acontecimento:

[...] haveria assim um jogo de força que visa manter uma regularização pré-existente com os implícitos que ela veicula, confortá-la como 'boa forma', estabilização parafrástica negociando a integração do acontecimento, até absorvê-lo e eventualmente dissolvê-lo; - mas também, ao contrário, o jogo de força de uma 'desregulação' que vem perturbar a rede dos 'implícitos' (PÊCHEUX, [1983] 2015, p. 47).

Para o autor, a repetição é antes de tudo um efeito material que fundamenta comutações e variações como um jogo de metáforas como outras possibilidades de articulação discursiva. E, sob esse jogo de forças, pode instaurar tanto a estabilização dos sentidos como também os deslocamentos e rupturas.

Cabe ainda observar que no espaço virtual, o objeto desta análise, o sujeito além de ser interpelado pela memória e pela ideologia, também já é afetado pelo lugar que ocupa na conjuntura social, como também pelas mídias digitais. Para a análise do processo discursivo sob as condições do virtual e digital, segundo Cortes (2015), deve-se levar em conta não apenas as mudanças tecnológicas que afetam o modo de ler, mas também as determinações históricas das leituras e ao mesmo tempo a história de tais determinações; e acrescenta: 
Isto implica considerar o funcionamento contínuo da ideologia e da memória no espaço/tempo da web; há de se considerar a historicidade, a exterioridade inscrita nos dizeres, no confronto com dizeres já ditos ou não ditos, já lidos, bem como rememorar outros também já esquecidos (CORTES, 2015, p.179).

Segundo Grigoletto (2011), no ambiente virtual, todo discurso é afetado pelo espaço em sua prática discursiva, uma teia não-linear, saturada de links, nós, lacunas, que supostamente possibilitam a deriva de sentidos para qualquer direção. "O espaço virtual constitui-se assim num espaço simbólico, marcado por contradições, por silenciamentos, por múltiplas vozes (algumas anônimas, outras não) que se (con)fundem numa trama de sentidos" (GRIGOLETTO, 2011, p. 53).

Nesta nova dinâmica de se comunicar com o mundo, Dias (2016) lembra que devemos estar atentos, "essas consequências têm a ver com o digital e com o modo como ele coloca em relação sujeito e conhecimento, através de um funcionamento específico da memória, cuja natureza é digital" (DIAS, 2016, p. 09). Desse modo, o discurso funciona com especificidades na mídia digital e pode intervir na produção dos sentidos; é sob as condições de produção do/no discurso digital que analisaremos a movimentação dos sujeitos e dos sentidos no discurso das matérias publicadas nos portais UOL e G1.

Neste espaço virtual de disputa também será observada a noção de silenciamento, não menos relevante para $\mathrm{AD}$, que é constitutiva do discurso, também importante para esta análise. De acordo com o pensamento de Pêcheux ([1983] 2015), o sentido sempre pode ser outro, por isso é necessário investigar as diversas relações estabelecidas no processo discursivo, sendo que:

O princípio dessas leituras consiste, como se sabe, em multiplicar as relações entre o que é dito aqui (em tal lugar), e dito assim e não de outro jeito, com o que é dito em outro lugar e de outro modo, a fim de se colocar em posição de 'entender' a presença de não-ditos no interior do que é dito (PÊCHEUX, [1983] 2015, p. 44).

Segundo Orlandi (2007), o silêncio é constitutivo de sentido, pois "o silêncio não é vazio, ou o sem-sentido; ao contrário ele é o indício de uma instância significativa. Isso nos leva à compreensão do 'vazio' da linguagem como horizonte e não como falta” (ORLANDI, 2007, p. 68). A autora faz distinção entre duas formas do silêncio: o silêncio fundador e a política do silêncio. Para ela, o silêncio fundador significa por si mes- 
mo. Já a política do silêncio produz um recorte entre o que se diz e o que não se diz e se divide em duas partes, o silêncio constitutivo e o silêncio local. No silêncio constitutivo se diz "X" para não dizer "Y”. Já o silêncio local é a manifestação mais visível desta política, é a interdição do dizer, a censura.

Assim, iniciaremos a análise da nossa primeira sequência discursiva (SD1)

\section{Análise}

SD1:

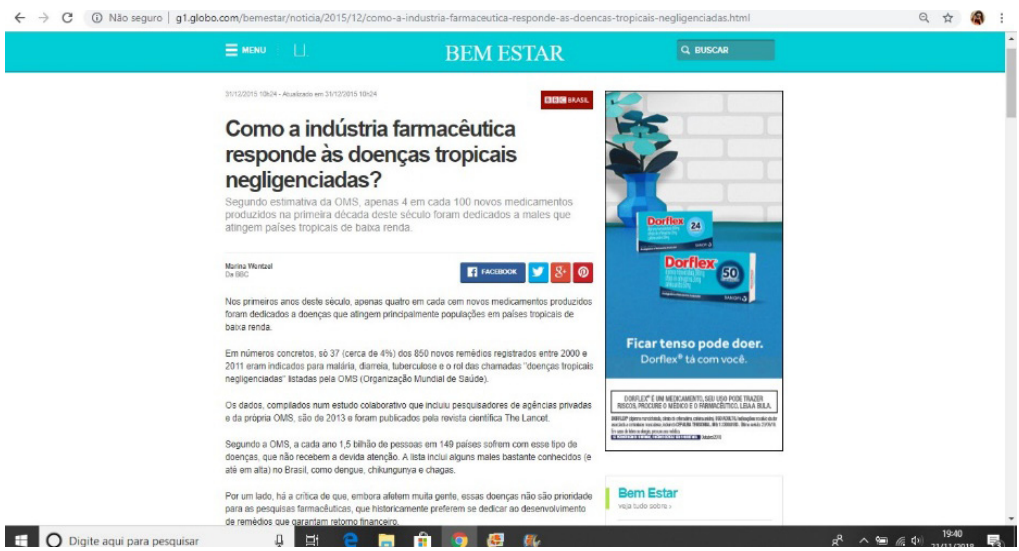

Figura 1: composta por um print da publicação do portal G1 no endereço-http://g1.globo. com/bemestar/noticia/2015/12/como-a-industria-farmaceutica-responde-as-doencas-tropicais-negligenciadas.html

A SD1 apresenta uma notícia produzida pela $\mathrm{BBC}-\mathrm{Brasil}^{3}$ que foi publicada no portal G1, canal Bem Estar, no dia 31/12/2015 com o título: "Como a indústria farmacêutica responde às doenças tropicais negligenciadas". No lide (SD1) temos o dito: "Segundo estimativa da OMS,

3 A BBC é uma agência jornalística britânica que foi criada em 1926 e é considerada atualmente a organização de transmissão mais antiga do mundo. No Brasil começou a sua operação em 1938, durante a Segunda Guerra Mundial. A presença da BBC Brasil na internet começou em 1999, tendo desde então um crescimento contínuo. Além do seu próprio site, o conteúdo jornalístico da BBC Brasil aparece em vários sites parceiros, entre eles os principais portais e sites de notícias do país. https://www.bbc.com/portuguese/institutional/090120_expediente_tc2.shtml 
apenas 4 (quatro) em cada (cem) 100 novos medicamentos produzidos na primeira década deste século foram dedicados a males que atingem países tropicais de baixa renda".

Verificamos, portanto, que a posição-sujeito que funciona no discurso jornalístico (SD1) é de denúncia contra a indústria farmacêutica em ralação ao pouco investimento para eliminação das DTNs. Ou seja, denuncia o jogo de interesse econômico que está acima das demandas sociais por medicamentos. Apesar de quase 26 milhões de pessoas no Brasil estarem sob o risco destas doenças, há um baixo interesse deste setor sobre esse tema, justificado pelo reduzido potencial de retorno lucrativo para as indústrias, uma vez que a população de baixa renda é a mais atingida, em sua maioria, em países de desenvolvimento (BRASIL, 2018).

$\mathrm{Na}$ SD1, funciona também o efeito-sentido de negligência social das indústrias farmacêuticas; logo, tomando a língua em sua opacidade, cabe aqui algumas perguntas: de quem é a negligência, afinal? Por que e por quem tais doenças e suas vítimas são negligenciadas? Notamos que as DTNs são discursivizadas como doenças da pobreza, sendo esse efeito de sentido determinado pelo imaginário de pobreza tanto dos sujeitos doentes, quanto das próprias doenças. Segundo Orlandi ([1999]2015), as projeções imaginárias permitem que os sujeitos passem das situações empíricas - os lugares dos sujeitos - para as posições discursivas. Nas palavras da autora:

Em toda língua há regras de projeção que permitem ao sujeito passar da situação (empírica) para a posição (discursiva). O que significa no discurso são essas posições. E elas significam em relação ao contexto sócio-histórico e à memória (o saber discursivo, o já-dito) (ORLANDI, [1999] 2015, p. 38).

Logo, pobreza e DTNs se constituem, portanto, em um ciclo, que é reconhecido pelo próprio Ministério da Saúde BRASIL (2018), como podemos verificar nas próximas SDs deste trabalho. 
SD2:

\begin{abstract}
A questäo do acesso (e da qualidade)
Além de criticar a falta de investimento suficiente em soluções para as doenças que atingem populações carentes, especialistas e ativistas chamam atenção para outro obstáculo: a falta de acesso a tratamentos eficazes e de qualidade
\end{abstract}

\begin{abstract}
Um dos exemplos é a malária, que, embora não conste da lista da OMS de males negligenciados, é endêmica nos países da África Subsaariana, gigantesca parte do continente localizada ao sul do deserto do Saara e que concentra alguns dos paises mais pobres do mundo
\end{abstract}

Embora tenha havido, desde a virada do milênio, uma queda de $37 \%$ nos casos e de $60 \%$ nos óbitos, a OMS estima o surgimento de 214 milhões de novos casos da doença neste ano, dos quais 438 mil resultaram em mortes - cerca de $90 \%$ delas na África.

Gabriel Alcoba, conselheiro para doenças tropicais da ONG Médicos Sem Fronteiras, diz ser frustrante tentar fazer medicamentos contra a doença chegarem a todos os atingidos nessas populações

"Às vezes não há remédios suficientes, em especial quando há um grande surto e precisamos fazer a administração em massa", diz o médico.

Segundo ele, o problema não é só levar medicamentos a esses locais, mas também o tipo de droga oferecida.

Alguns remédios mais antigos não surtem efeito e chegam, segundo o especialista, a atrapalhar o tratamento, pois podem levar à resistência do parasita.

Figura 2: composta por um print da publicação do portal G1 no endereço-http://g1.globo. com/bemestar/noticia/2015/12/como-a-industria-farmaceutica-responde-as-doencas-tropicais-negligenciadas.html (grifo do autor) ${ }^{4}$

A SD2 é constituída do texto com o título: "A questão do acesso (e da qualidade) " e apresenta alguns dados sobre a situação das DTNs naquele ano, como também as dificuldades de acesso aos medicamentos, principalmente quando há uma situação de surto: “Às vezes não há remédios suficientes, em especial quando há um grande surto e precisamos fazer a administração em massa", diz o médico Gabriel Alcoba da organização Médicos Sem Fronteira (MSF).

Na SD2, o que primeiro chama atenção é o destaque do título que colocou em parênteses o termo "qualidade" que poderia ter vindo entre aspas ou sem nada, mas foi apresentado dessa forma. Parafraseando a formulação, temos: "A questão do acesso e da/com qualidade". Nesta condição está posto aqui o efeito metafórico que seria o fenômeno semântico produzido por uma substituição contextual, “[...] para lembrar que este 'deslizamento de sentido' entre x e y é constitutivo de 'sentido' designado por x e y” (PÊCHEUX, [1975] 2014, p.96).

4 Para a captura da imagem na tela do computador foi utilizada a ferramenta Lightshot. Após a captura foi realizada o grifo da imagem com recurso pincel disponibilizado pela ferramenta. 
Dessa forma, é possível observar o jogo de interesse da indústria farmacêutica e ao mesmo tempo observar a dificuldade para o tratamento das DTNs em regiões pobres do planeta. Há aqui, assim como na SD1, o funcionamento da memória discursiva sobre a doença de pobre, o que supostamente justificaria o não interesse da produção de fármacos.

A notícia é finalizada com a seguinte informação: "A empresa suíça Novartis afirma ter entregue, sem obter lucro, mais de 300 milhões de tratamentos com ACTs para o combate à malária". Nessa formulação materializa um efeito de sentido de "bondade" da indústria que supostamente "abriu mão" de um lucro de 300 milhões de reais, mas que é revertido em capital social, pois tal ação é convertida no quesito responsabilidade social coorporativa, tendo como meta a premiação da Access To Medicine Foudation mantida pela Fundação Bill \& Melina Gates. No entanto, segundo Aguiar (2016, p.21) tal prática também é considerada por alguns autores como motivo de perpetuação da negligência, já que tais doenças não estão associadas apenas às condições biológicas, mas, sobretudo aos determinantes sociais da pobreza, neste caso, a doação de medicamentos apenas perpetua as condições de iniquidades das populações atingidas por estas doenças.

Conforme Aguiar (2016, p.68 ), a doação de medicamentos começou em 1987 com o Programa Mundial de Doação de Mectizan, ou seja, há mais de 30 anos esta tem sido uma prática que conta com o incentivo da OMS, que considera esta ação como estratégica para o combate às DTNs, sendo o Brasil beneficiado com a doação de medicamentos para o combate de quatro agravos negligenciados: oncocercose, geohelmintíases, filariose linfática e hanseníase das empresas Merck \& Co. Inc., GlaxoSmithKline, Eisai, Merck KGaA, Novartis e Pfizer, (AGUIAR, 2016, p. 21). Conforme a autora, esta prática é silenciada pelo MS em documentos oficiais relativos ao enfretamento a estas enfermidades, o que produz um efeito de omissão e negligência governamental ao não investir na compra de medicamentos. Assim, as discursividades inscritas nas duas sequências discursivas (SD1 e SD2) funcionam com a posição-sujeito de denúncia e resistência ao discurso de negligência da indústria farmacêutica, que visa somente interesses econômicos.

Destacamos, em especial, o discurso da Ong MSF (SD2), que funciona com efeitos de sentidos de resistência à exclusão social, que, para Minayo (2000) seria o resultado das configurações estruturais que vem se desenrolando ao longo da história na América Latina como resultado das políticas de integração do capital global. 
A exclusão pode ser definida como um processo múltiplo de separação de grupos e sujeitos, presente e combinado com as relações econômicas, sociais, culturais e políticas, que resulta na pobreza, discriminação, não acesso ao mundo do trabalho e do consumo, e não representação social e pública" (MINAYO, 2000, p. 56) $)^{5}$.

Minayo (2000, p.56) cita como exemplo a situação do Brasil que vem aumentando este estado de exclusão social, pois são populações consideradas supérfluas para o mercado de produção e consumo. E assim fica fácil de entender a relação de produção e consumo, pois se não temos consumidores e compradores, não há motivo para a indústria farmacêutica produzir medicamentos para cura destes males negligenciados, que é objeto do discurso dos leitores desta publicação, nas sequências discursivas apresentadas a seguir.

Bloco II - SD3, SD4, SD5 e SD6:

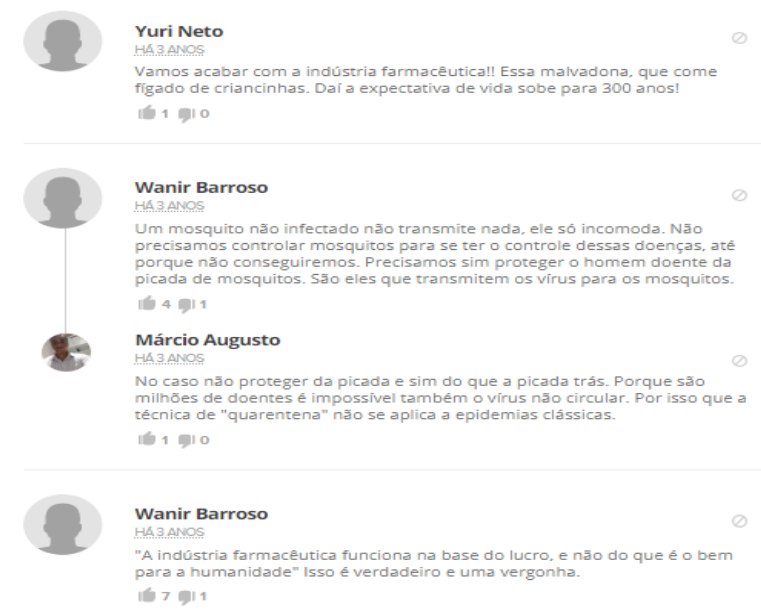

Figura 3: composta por um print da publicação do portal G1 no endereço- http://g1.globo. com/bemestar/noticia/2015/12/como-a-industria-farmaceutica-responde-as-doencas-tropicais-negligenciadas.html

5 Tradução livre das autoras: "La exclusion puede ser definida com un proceso mútiple de separación de grupos y sujetos, presente y combinado em las relaciones económicas, sociales, culturales e polyticas, resultando de él, pobreza, discriminacion, no accesibilidad al mundo del trabajo y del consumo, y no representación social y pública" (MINAYO,2000, p. 56) 
As SDs 3 a 6 foram constituídas de quatro comentários dos leitores, sobre a notícia da SD1.

SD3: "Vamos acabar com a indústria farmacêutica!! Essa malvadona, que come fígado de criancinhas. Daí a expectativa de vida sobe para 300 anos!”.

SD4: "A indústria farmacêutica funciona na base do lucro, e não do que é o bem para a humanidade" Isso é verdadeiro e uma vergonha".

Observa-se que o discurso materializado nos comentários da SD3 e SD4 funciona com efeitos de sentidos contrários ao posicionamento da indústria farmacêutica, ou seja, há efeitos de resistência ao discurso da negligência dessas empresas. Vejamos mais algumas sequências discursivas:

SD5: "Um mosquito não infectado não transmite nada, ele só incomoda. Não precisamos controlar mosquitos para se ter o controle dessas doenças, até porque não conseguiremos. Precisamos sim proteger o homem doente da picada de mosquitos. São eles que transmitem os vírus para os mosquitos".

A SD6 "No caso não proteger da picada e sim do que a picada trás. Porque são milhões de doentes é impossível também o vírus não circular. Por isso que a técnica de "quarentena" não se aplica a epidemias clássicas".

Já nos discursos das SD5 e SD6 funciona o efeito de sentido de especialista no assunto como ponto central da discursividade. Mas também funciona no discurso dos comentários (SDs 5 e 6) a posição-sujeito de denúncia do descaso do poder público pela maneira como o Brasil vem tratando as questões sobre as doenças transmitidas por mosquitos, a exemplo do trecho da SD4: "Precisamos sim proteger o homem doente da picada de mosquitos". Prosseguindo, temos a SD7:

SD7:

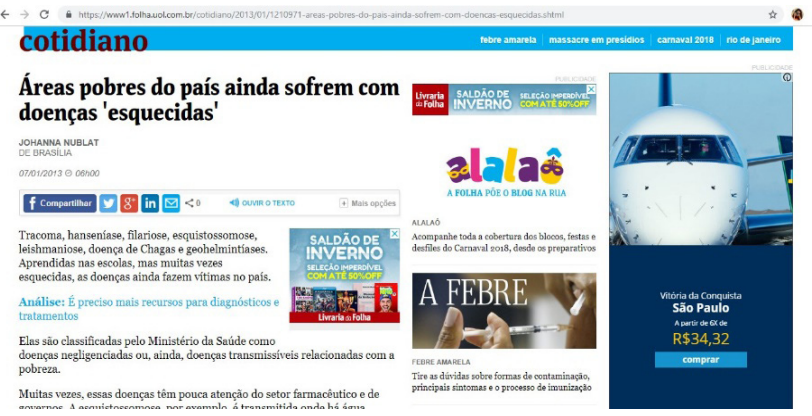

Figura 4: composta por um print da publicação do portal UOL no endereço- https:// www1.folha.uol.com.br/cotidiano/2013/01/1210971-areas-pobres-do-pais-ainda-sofrem-com-doencas-esquecidas.shtml 
A SD7 traz um print da notícia publicada no site UOL na página da Folha em 07/01/2013 com a manchete: "Áreas pobres do país ainda sofrem com doenças "esquecidas".

No lide da matéria: "Tracoma, hanseníase, filariose, esquistossomose, leishimaniose, doença de Chagas e geohelmitíases. Aprendidas nas escolas, mas muitas vezes esquecidas, as doenças ainda fazem vítimas no país".

Nesta SD, o nome "negligenciada" foi substituído por "esquecidas", uma paráfrase que vem reforçar o efeito de sentido de pobreza à discursivização das DTNs. A posição-sujeito desta SD é também de denúncia quanto ao grave problema social das DTNs no Brasil vinculadas às condições de pobreza. Instaura-se um efeito de memória, na relação com o imaginário discursivo sobre as DTNs, historicamente determinadas e associadas à pobreza.

Vejamos a SD8:

SD8:

Elas são classificadas pelo Ministério da Saúde como

doenças negligenciadas ou, ainda, doenças transmissíveis relacionadas com a pobreza.

Muitas vezes, essas doenças têm pouca atenção do setor farmacêutico e de governos. A esquistossomose, por exemplo, é transmitida onde há água contaminada.

Em comum, matam pouco ou devagar, afetam mais pobres e se concentram em áreas rurais ou marginalizadas. No país, a maior parte está no Norte, Nordeste e Centro-Oeste.

"Você não precisa fazer advocacia de epidemia, dizer 'dengue é importante'. Já essas doenças, a sociedade não percebe mais", diz Jarbas Barbosa,

secretário de vigilância em saúde do ministério.

Em 2010, por exemplo, 34,9 mil novos casos de hanseníase foram registrados. Doenças que provocam mobilização, como os casos graves de dengue e de Aids, tiveram 17,5 mil e 34,2 mil registros, respectivamente, no mesmo ano.

Os desafios são medicamentos mais modernos, políticas de governo mais afinadas e, ainda, uma maior mobilização dos médicos, aponta Eric Stobbaerts, diretor-executivo da DNDi (Iniciativa de Medicamentos para Doenças Negligenciadas) no país.

Figura 5: composta por um print da publicação do portal UOL no endereço https:// www1.folha.uol.com.br/cotidiano/2013/01/1210971-areas-pobres-do-pais-ainda-sofrem-com-doencas-esquecidas.shtml (grifo do autor)

Da SD8 destacamos a fala do secretário de Vigilância em Saúde do Ministério da Saúde Jarbas Barbosa: "Você não precisa fazer advocacia de epidemia, dizer 'dengue é importante'. Já essas doenças, a so- 
ciedade não percebe mais". No discurso oficial do MS (trecho da SD8), funciona o efeito de sentido de que as DTNs são também ignoradas e esquecidas pela sociedade, logo, não merecem atenção ou interesse governamental, enquanto a dengue é uma doença que apesar de estar no rol das doenças classificadas como negligenciadas pela OMS, aqui no Brasil também atinge pessoas das classes média e rica, por isso "dengue é importante". O dito "a sociedade não percebe mais" produz efeitos de homogeneidade ou igualdade social, um efeito ideológico, já que ao ultrapassar o efeito de transparência da linguagem, questiona-se: qual sociedade não percebe mais? Isso abrange toda a sociedade brasileira, até mesmo os desprezados e abandonados em suas mazelas biológicas e sociais?

Assim, o discurso do MS (SD8) funciona com efeito de silenciamento ao tema sugerido, "essas doenças, a sociedade não percebe mais" e, ao mesmo tempo tanto determina, quanto reforça o imaginário "doenças de pobre", porque estão presentes em sua maioria nas regiões pobres do Brasil, como mostra a SD9:

SD9:

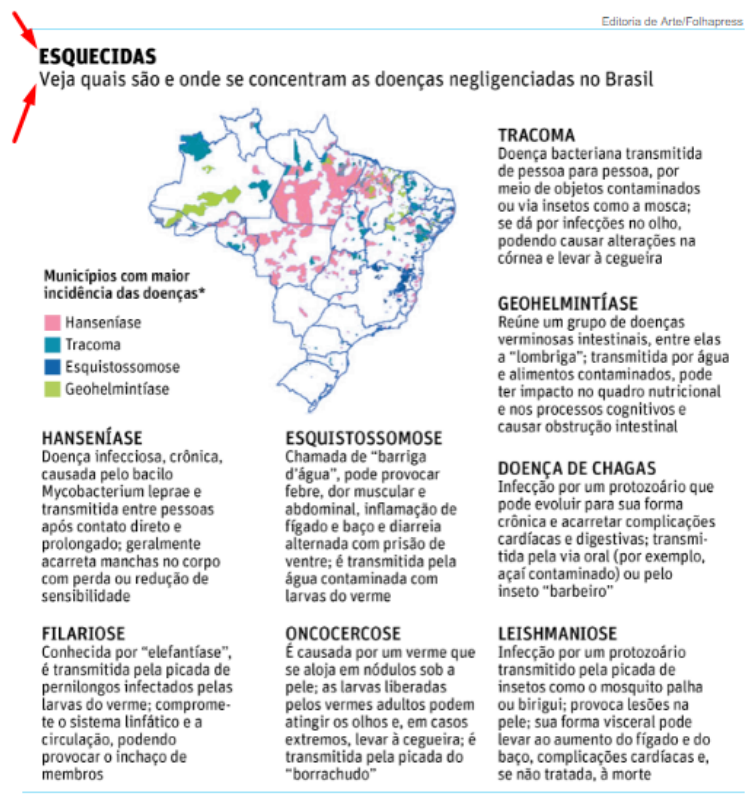

Figura 6: composta por um print da publicação do portal UOL no endereço- https:// www1.folha.uol.com.br/cotidiano/2013/01/1210971-areas-pobres-do-pais-ainda-sofrem-com-doencas-esquecidas.shtml (grifo do autor) 
A SD9 é constituída de uma imagem e da formulação da notícia que traz como título: "Esquecidas: Veja quais são e onde se concentram as doenças negligenciadas no Brasil", além de um mapa do Brasil, que destaca as cores do glossário dos Municípios com maior incidência das doenças.

$\mathrm{Na}$ ilustração nota-se que as regiões Norte e Nordeste estão bem coloridas, o que mostra uma presença forte das DTNs. Já as regiões Sul e Sudeste estão praticamente sem cores, demonstrando a ausência das doenças. Desse modo, nesta SD funciona a posição-sujeito de denúncia à negligência e ao abandono não somente das DTNs, mas também às regiões Norte e Nordeste, que por determinações de fatores históricos, climáticos, sociais e econômicos são as regiões mais pobres do Brasil:

O Nordeste é, em grande medida, filho das secas; produto imagético-discursivo de toda uma série de imagens e textos, produzidos, a respeito deste fenômeno, desde a grande seca de 1877 veio a colocá-lo como problema mais importante desta área (ALBUQUERQUE JR., 1999, p.68).

Segundo Albuquerque Jr. (1999, p.66) este discurso e todas as suas derivações constituem o Nordeste como um recorte espacial especifico do Brasil, esquecido pelo poder público por ser uma região que carrega o imaginário do flagelo da seca e da pobreza, uma determinação histórica que perpétua nos dias atuais e que por conta disso é o território ideal para o desenvolvimento do grupo de doenças negligenciadas que persistem no país e que são citadas no texto analisado na SD 10.

SD10:

\section{TESTE EM MASSA}

Barbosa diz que ajustes nas estratégias permitiram que o país esteja perto de eliminar a filariose na região de Recife e a oncocercose entre Yanomamis últimos focos dos males.

É possível que se atinja neste ano a meta para 2015 de menos de um caso de hanseníase para cada 10 mil habitantes.

Em março, o ministério fará campanha em escolas de ao menos 800 municípios para achar casos de hanseníase. Filariose, tracoma e geohelmintíases também serão tratadas.

Figura 7: composta por um print da publicação do portal UOL no endereço- https:// www1.folha.uol.com.br/cotidiano/2013/01/1210971-areas-pobres-do-pais-ainda-sofrem-com-doencas-esquecidas.shtml (grifo do autor) 
A SD10 traz um subtema da notícia apresentada na SD7: “Teste em Massa" com apresentação de ações governamentais para eliminação de algumas DTNs do Brasil.

Nesta SD, na materialidade discursiva da sequência, embora funcione efeitos de sentidos de combate à negligência do Ministério da Saúde, pela meta de eliminação de algumas doenças e diminuição de outras, ao mesmo tempo, produz efeitos de sentidos de que as DTNs são doenças localizadas em regiões consideradas pobres, já que os dados trazem novamente as regiões consideradas pobres do Brasil como alvo da campanha, ao citar uma capital nordestina e uma aldeia indígena da região norte. E assim, a discurzivização das DTNs se dá com efeitos de sentidos não somente de pobreza, mas de uma região especificamente pobre, qual seja, a região nordeste. Instaura-se aqui um efeito parafrástico de sentidos com a SD9, a pobreza regionalizada, determinada historicamente.

\section{Conclusões Preliminares}

A discursivização das DTNs nas notícias aqui apresentadas do site UOL e do portal G1 produz efeitos de sentidos de resistência frente à situação de descaso a estas doenças e suas vítimas, sendo tal processo sintomas da desigualdade social do país. Ou seja, funciona uma posição-sujeito de denúncia às indústrias farmacêuticas pela negligência para com as DTNs e suas vítimas. Tal negligência é motivada pelo jogo de interesses econômicos, e assim as empresas não demonstram empenho em produzir medicamentos para doenças de pessoas pobres, já que essa produção não traz lucratividade. Tal descaso produz efeitos de uma grande irresponsabilidade social da indústria farmacêutica, posicionamento que funciona com a anuência do poder público, logo, também responsável por tal negligência, já que não se dá o enfrentamento da situação.

Vimos também a distribuição espacial das doenças que são esquecidas, por estarem presentes nas áreas construídas imaginariamente como as mais pobres do Brasil. Assim, o desinteresse e a distribuição espacial das doenças estão atravessados pelo discurso do lucro, um descomprometimento frente às responsabilidades sociais, o que reforça o imaginário de DTNs como "doença de pobre", que é o fator de maior relevância para permanência dessas doenças no Brasil, segundo o próprio Ministério da Saúde. Portanto, a pobreza tanto é um determinante quanto é determinada por esse processo de negligência social. 
Isso nos faz pensar no discurso da negligência com efeitos de sentidos de descuido, descaso, omissão por parte do poder público e das indústrias farmacêuticas, que só começaram a se movimentar no sentido contrário à negligência após a cobrança da Organização Mundial de Saúde (OMS), há pouco mais de uma década.

Foi possível ainda verificar o funcionamento do discurso de "doação" das indústrias fármacas, que produz efeitos de sedimentação do sentido de negligência, que também se inscreve no discurso estatal, que se exime de suas responsabilidades, e, assim, reforça ainda mais os efeitos de negligência frente à desigualdade social, que é a doença mais grave que afeta o país, onde se encontra a raiz de outros males, a exemplo das DTNs.

\section{REFERÊNCIAS}

AGUIAR, Raquel. Fazer o bem sem ver a quem? Visibilidades e invisibilidades discursivas na doação de medicamentos para doenças negligenciadas/ Raquel Aguiar. Rio de Janeiro, 2016.

ALBUQUERQUE JR., Durval Muniz de. A Invenção do Nordeste e Outras Artes. FJN/Ed. Massagana, SP: Cortez, 1999.

BRASIL. Ministério da Saúde. Secretaria de Vigilância em Saúde. Saúde Brasil 2017: uma análise da situação de saúde e os desafios para o alcance dos Objetivos de Desenvolvimento Sustentável. Brasil, 2018.

BRASIL. Ministério da Saúde. Departamento de Ciência e Tecnologia. Doenças negligenciadas: estratégias do Ministério da Saúde. Brasil, 2010.

CORTES, G. R. O. Movimentos sociais, interlocução discursiva a (re) territorialização do ciberespaço: Uma análise da greve de professores estaduais da Bahia em 2012. In: . VIII Seminário Internacional As Redes Educativas e as Tecnologias: Movimentos Sociais e Educação, Junho/2015.

, G. R. O. Do lugar discursivo ao efeito-leitor: a movimentação do sujeito no discurso em blogs de divulgação científica / Gerenice Ribeiro de Oliveira Cortes. - Recife: O Autor, 2015.

DIAS, Cristiane. A análise do discurso digital: um campo de questões. In: REDISCO, Vitória da Conquista, v. 10, n. 2 , p. 8-20, 2016 .ISSN 2316-1213 FERNANDES, Carolina; VINHAS Luciana Iost. Da maquinaria ao dispositivo teórico-analítico: a problemática dos procedimentos metodológicos da Análise do 
Discurso. In: . Linguagem em (Dis)curso - LemD, Tubarão, SC, v. 19, n. 1, jan./abr. 2019, p. 133-151.

Grigoletto, E. O discurso nos ambientes virtuais de aprendizagem: entre a interação e a interlocução. In: . E. Grigoletto, F. S. Nardi, \& C. R. Schons (Org.), Discursos em rede: práticas (re) produção, movimentos de resistência e constituição de subjetividades no ciberespaço. Recife, PE: Editora Universitária-UFPE, 2011, p. 47-78.

MINAYO, Maria Cecília de Souza. Condiciones de vida, desigualdad y salud a partir del caso brasilenõ. In: Salud y equidade: una mirada desde las ciências sociales. /Coordenaod por Roberto Bricenõ-León, Marica Cecília de Souza Mainayo e Carlos E. A. Coimbra jr . - Rio de Janeiro: Editora Fiocruz, 2000, p. 55-71.

ORLANDI, E. Análise de Discurso: princípios \& procedimentos. Campinas: Pontes,[1999] 2015.

. As formas do silêncio: No movimento dos sentidos. Campinas: Unicamp, 2007.

. Discurso, Imaginário Social e Conhecimento. In: . Em Aberto, Brasília, ano 14, n.61, p.53-59, Jan./mar. 1994. Jan./Jun. 1996.

. Exterioridade e ideologia. Cad. Est. Ling., Campinas, (30): p.27-33, PÊCHEUX \& FUCHS Por Uma Análise Automática do Discurso. In: GADET \& HAK (org). Por uma análise automática do discurso: uma introdução à obra de Michel Pêcheux.5a edição. Campinas: Ed. Unicamp, [1969] 2014.

. Semântica e Discurso: Uma crítica à afirmação do óbvio. Tradução: Eni Pulcinelli Orlandi [et al.] - 2. Ed. - Campinas, SP. Editora da UNICAMP, [1975] 2014.

[1983a] 2015.

- O Discurso: estrutura ou acontecimento. Campinas: Pontes, . O papel da memória. In: ACHARD, Pierre et al. Papel da Memória. $2^{a}$ ed. Campinas, SP: Pontes Editores, [1983] 2015.

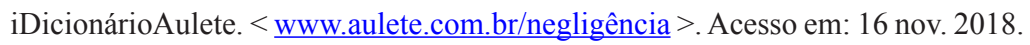

Recebido em: 30/07/2019

Aceito em: 05/01/2020 